\title{
Near Well Simulation and Modelling of Oil Production From Heavy Oil Reservoirs
}

\author{
A.Malagalage ${ }^{1,2} \quad$ Britt M. Halvorsen ${ }^{2}$ \\ ${ }^{1}$ Tel-Tek, Porsgrunn, Norway, Anjana.t.malagalage@tel-tek.no \\ ${ }^{2}$ Telemark University College, Faculty of Technology, Norway, Britt. Halvorsen@hit.no
}

\begin{abstract}
Heavy oil reservoirs cover up $2 / 3$ of the world's hydrocarbon reservoirs. When heavy oil is produced through horizontal wells with water drive, a water breakthrough is expected.

Conventional inflow control devices (ICDs) can only delay a water breakthrough. The disadvantage of ICDs is the inability to control the water inflow, after the water breakthrough. Autonomous inflow control valve (AICV) is designed to choke or stop the inflow as soon as the water breakthrough occurs.

To evaluate the performance of AICVs OLGA-Rocx simulations were conducted. Simulations show that the AICVs have a superior potential in limiting the water inflow to the base pipe $(86 \%$ reduction in water accumulation compared to normal ICDs). AICVs are more effective in heterogeneous and fractured reservoirs as it can restrict the early water breakthrough. In homogeneous reservoirs, AICVs' function reduces oil production rate compared to the ICD system, however, the lifetime of the well is increased.
\end{abstract}

Keywords: Near well simulation, Inflow control, heavy oil production, OLGA, ROCX, AICV

\section{Introduction}

Until recently heavy crude oil production was not considered economical and little interest was shown in heavy oil field explorations. It is estimated that the heavy crude oil and bitumen reserves cover up $2 / 3$ of the total crude oil reserves in the world. Development of oil recovery technologies and the continuous growth of the oil demand have increased the economic value of heavy oil. This has resulted in a significant boost in the heavy oil recovery.

When producing heavy oil, water/gas breakthrough can happen easily as water/gas have a higher mobility compared to heavy oil. When water/gas breakthrough occurs, oil production is reduced. Inflow control devices (ICDs) have to be used to overcome the issues of water/gas breakthrough.

Conventional ICDs are capable of delaying water/gas breakthrough but once the breakthrough occurs there is no other solution but to choke the total flow. Hence various developments have been emerged in the field of inflow control technology such as inflow control valves (ICVs). InflowControl has developed an autonomous inflow control valve (AICV) which can increase the oil recovery while overcoming the problem of water/gas inflow. The objective of AICV is to minimize the water/gas inflow from the zones where the breakthrough has occurred and to allow oil production from the other zones. It is interesting to study the effectiveness of AICVs compared to conventional ICDs, under different conditions. (Mathiesen 2013b)

\section{Literature review}

\subsection{Heavy oil production and its challenges}

Basically the major crude oil types can be categorized as light oil, heavy oil, extra heavy oil and natural bitumen. Currently Canada and Venezuela are the two major countries which explore heavy oil fields and in Canada about 700,000 barrels of heavy crude oil are produced per day (A. Hart 2013). Recovering heavy oil is a challenging and a costly process due to its higher viscosity. In a horizontal well, the distance that the oil has to move to reach the wellbore is relatively low. Therefore horizontal wells can be considered as a better technique to recover heavy oil. The main advantage of horizontal drilling over conventional vertical drilling is its higher production rates. As a result operating costs are relatively less compared to vertical drilling. The major obstacle in drilling a horizontal well is the higher capital costs compared to vertical wells. Generally the cost of drilling a new horizontal well from the surface is 1.5 to 2.5 times the cost of drilling a new vertical well. (S.D.Joshi 2003)

In most of the oil reservoirs oil is in contact with water and/or gas. As both water and gas have lower viscosities and hence higher mobility, water/gas breakthrough can occur during heavy oil recovery. Due to the toe-heel effect, higher oil production rate is obtained at the heel section of the well. Hence in a homogeneous reservoir, the initial water breakthrough will occur near the heel of the well. 


\subsection{Inflow control technologies}

In order to control the wellbore inflow profile, inflow control devices were introduced in early 90's. The basic working principle of different ICDs is to restrict the inflow by creating an additional pressure drop. As a result wellbore pressure distribution will be adjusted causing an evenly distributed inflow profile along the horizontal well.

According to (P. Fernandes 2009) an ICD can be effective when the pressure drop across the pipe line is relatively higher than the pressure difference between the well and the reservoir. Highly permeable reservoirs with long wells provide a favorable condition for ICDs. Furthermore if the frictional pressure drop is relatively low compared to the drawdown, ICDs can even restrict the oil flow instead of delaying water inflow. If the permeability distribution can be understood, ICDs can be effectively used in heterogeneous reservoirs to delay the water breakthrough. It can be concluded that the ICDs are not a universal solution for water breakthrough problem.

ICD is a fixed instrument. Once it is installed in a particular application, neither its location nor its relationship between the pressure drop and the flow rate can be changed. That is the reason for ICDs not being able to prevent water/gas inflow. Another type of inflow control technology that has been developed in order to overcome this drawback is the inflow control valve (ICV). Those are sliding-sleeve valves installed along the pipeline. By using a downhole monitoring system, ICVs can be operated by a controlling system which is located at the surface. ICVs exhibit a flexibility to operate according to the changing properties in the reservoir. ICVs are more expensive than ICDs and ICDs are more simple and reliable compared to ICVs as they have no moving parts, therefore ICDs have a less installation risks. (P. Fernandes 2009, F. T. Al-Khelaiwi 2010)

The newest inflow control technique is to use autonomous instruments which can adjust their functionality autonomously according to the dynamics of the wellbore. Autonomous inflow control devices are being developed by companies such as Halliburton and Statoil. Statoil has produced a rate controlled production (RCP) valve which chokes the low viscous flows while permitting high viscous flow to go through the valve. It operates autonomously based on the Bernoulli Effect. (M. Halvorsen 2012)

\subsection{Autonomous inflow control valve (AICV)}

AICV is a completely self-operating device, which has been designed by combining the features of both AICD and ICV. Its autonomous functionality is achieved by designing it in a way to distinguish between fluids based on their density and viscosity. Fundamental theory behind the operation of AICV is the difference between the pressure drop in a laminar flow restrictor and a turbulent flow restrictor.

Pressure drop within the laminar flow restrictor is analogous to a pipe segment and the pressure drop is given by the equation (1).

$$
\Delta P=\frac{32 \cdot \mu \cdot v \cdot L}{D^{2}}
$$

In a turbulent restrictor, pressure drop can be related with a thin orifice plate and the relevant pressure drop is given by equation (2).

$$
\Delta P=K \cdot \frac{1}{2} \cdot \rho \cdot v^{2}
$$

Where,

$$
\begin{array}{cl}
\Delta P & : \text { Pressure drop } \\
K & : \text { Geometric constant } \\
D & : \text { Diameter of the tube } \\
L & : \text { Length } \\
\mu & : \text { Viscosity } \\
v & : \text { Fluid velocity } \\
\rho & : \text { Density }
\end{array}
$$

According to these relations, pressure drop within a laminar flow restrictor depends on the viscosity and the velocity of the fluid. In a turbulent restrictor, the pressure drop depends on the density and the velocity of the fluid.

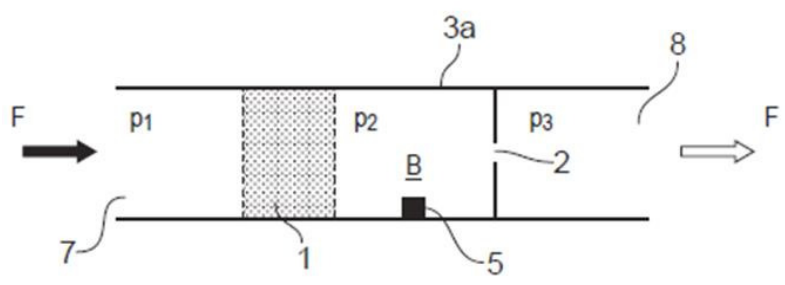

Figure 1. Combination of laminar and turbulent restrictors in series (Mathiesen 2013a)

AICV consists of a component which can be considered as a laminar flow restrictor and a turbulent flow restrictor connected in series which is shown in Figure 1. Laminar flow restrictor is represented by section 1 while the turbulent restrictor is represented by section 2. As the fluid enters the inlet (section 7) it has to go through both flow restrictors. Depending on the fluid characteristics, pressure in chamber B will vary. Pressure in chamber B is used to control the valve. When a high viscous fluid (oil) goes through the laminar flow restrictor, a higher pressure drop will occur according to (1). When a low viscous fluid (water) passes through the laminar flow restrictor, it will result in a relatively low pressure drop. When a low viscous fluid (water) passes through the laminar flow restrictor, it will result in a relatively low pressure drop resulting a higher pressure in the chamber.

$\mathrm{AICV}$ is designed to be opened when the pressure in chamber B (P2) is relatively lower than the pressure in the inlet section (P1). That is when a higher pressure drop occurs via the laminar flow restrictor at section 1 , 
AICV will kept open. When oil flows through the restrictors, relatively higher pressure drop occur through section 1 due to its high viscosity. As a result the pressure in chamber $\mathrm{B}$ will be lowered and the valve will be kept open. When a low viscous fluid (gas/water) flows through the restrictors relatively lower pressure drop will occur through the laminar restrictor. This will result in a relatively higher pressure in chamber $\mathrm{B}$, which will force the valve to be closed. (Mathiesen 2013a)

\subsection{Near-well simulations}

Conventional reservoir and well simulators are not sophisticated enough to simulate phenomena like coning where dynamic wellbore-reservoir interactions play a major role. A steady state inflow performance relationship (IPR) is being used in conventional dynamic well flow models. This method does not account for the dynamics in the near well zone. At the same time steady state lift curves are used by the conventional reservoir models to represent a tubing performance relationship (TPR) which again does not consider the flow dynamics in the wellbore. This drawback can be overcome by combining a transient wellbore flow model with a near-well reservoir model. (B. $\mathrm{Hu}$ 2007)

OLGA-ROCX is one of the leading commercially available transient wellbore-reservoir flow models. In (R. A. F. S. Moghaddam 2013) OLGA-ROCX has been used to study the application of ICD in heavy oil production and it was successfully implemented for oil with viscosity of $100 \mathrm{cp}$ and 500cp. A thorough analysis between AICVs and ICDs were done in (Mathiesen 2013a) using OLGA-ROCX under different conditions in the well. As successful simulations have been conducted with AICV and ICD, OLGA-ROCX was used to conduct the simulations in this research.

\section{Development of the OLGA-Rocx model}

\subsection{Development of the reservoir model}

\subsubsection{Grid}

The dimensions of the considered reservoir are mentioned in Table 1. Generally an AICV is installed per a zone having a length of $12.4 \mathrm{~m}$ of the well. It is difficult to simulate a real well with several AICVs as it requires significant amount of computational resources. Hence an equivalent AICV was selected to represent 8 AICVs. Therefore the length of the well zone containing the equivalent $\mathrm{AICV}$ is $99.2 \mathrm{~m}$.

Table 1. Dimensions of the reservoir

\begin{tabular}{|l|l|}
\hline Length of the reservoir (x) & $992 \mathrm{~m}$ \\
\hline Height of the reservoir $(\mathrm{z})$ & $20 \mathrm{~m}$ \\
\hline width of the reservoir $(\mathrm{y})$ & $80 \mathrm{~m}$ \\
\hline
\end{tabular}

The horizontal well that is being simulated is located parallel to the $\mathrm{x}$-direction. Location of the well in yzplane is shown in Figure 2.

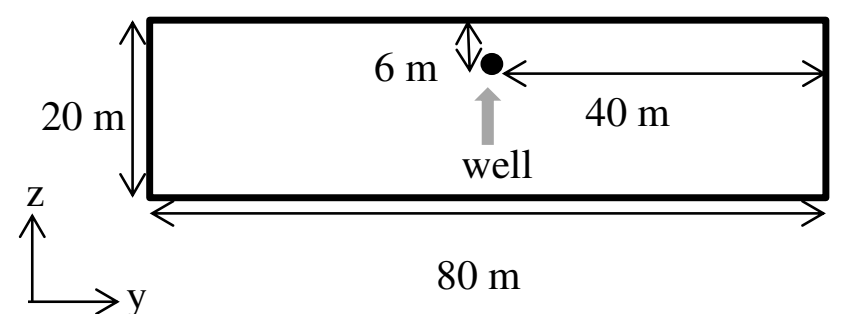

Figure 2. Location of the well in the yz-plane

When developing the mesh for the simulations, a mesh converging towards the center can be applied in $y$ ddirection to have a finer mesh around the well. For $\mathrm{x}$ and z-directions uniform meshes were applied. The mesh was divided into 29 elements along the y-axis and it was divided into 10 elements along both $\mathrm{x}$ and $\mathrm{z}$ directions. The final mesh is shown in Figure 3.

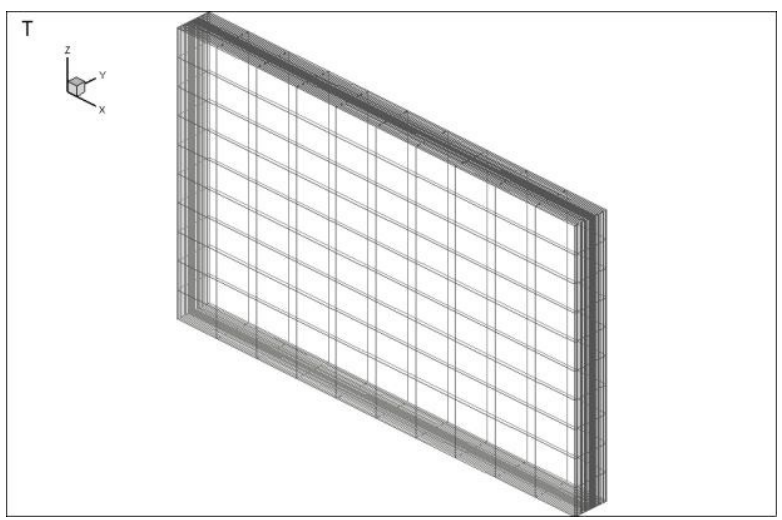

Figure 3. 3D view of the grid

\subsubsection{Fluid properties}

Under the fluid properties, black-oil model was selected. Black-oil model is a simplified model which can be used for systems which are not highly volatile (Peaceman 2000).The basic properties of heavy oil and the conditions of the reservoir that were considered in the simulations are given in Table 2.

Table 2. Reservoir and oil properties used for simulations

\begin{tabular}{|l|l|}
\hline Oil viscosity & $150 \mathrm{cp}\left(\right.$ at $\left.130 \mathrm{bar}, 100^{\circ} \mathrm{C}\right)$ \\
\hline Oil specific gravity & 0.92 \\
\hline Gas specific gravity & 0.64 \\
\hline GOR $\left(\mathrm{Sm}^{3} / \mathrm{Sm}^{3}\right)$ & 50 \\
\hline
\end{tabular}

For simulating a case with water drive, two feed steam have to be defined. The respective feed streams are defined in Rocx as tabulated in Table 3. 
Table 3. Feed streams

\begin{tabular}{|l|l|l|l|}
\hline Stream & Fraction type & Fraction & Watercut \\
\hline Oil & GOR & 50 & 0.0001 \\
\hline Water & GLR & 0.0001 & 0.99 \\
\hline
\end{tabular}

\subsubsection{Reservoir properties}

For all the simulations, porosity of the reservoir was considered as 0.3 which is constant throughout the reservoir. Three types of reservoirs based on their permeability profiles were considered in this study. Those three types are,

- Heterogeneous reservoir with a highly permeable zone (fractured reservoir)

- Heterogeneous reservoir with a relatively high permeable zone and with a relatively lower permeable zone.

- Homogeneous reservoir

In each cell of all reservoirs, permeability in horizontal directions $\left(\mathrm{k}_{\mathrm{H}}\right)$ ( $\mathrm{x}$ and $\mathrm{y}$ directions) was considered 10 times higher than the vertical permeability $\left(\mathrm{k}_{\mathrm{V}}\right)$ (z-direction) of that particular cell. Vertical permeability profiles of the three reservoirs are shown in Figure 4.

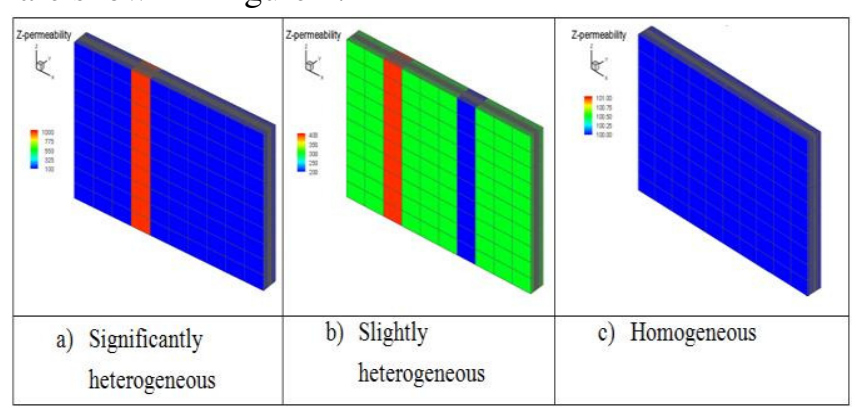

Figure 4. Vertical permeability profiles of the reservoir

\subsubsection{Initial and boundary conditions}

Initially black oil feed is defined as $100 \%$ oil and initially reservoir is considered to be completely saturated with oil. The pressure in the reservoir is 130 bar and the temperature is $100^{\circ} \mathrm{C}$

\subsection{Development of the well and wellbore model}

\subsubsection{Wellbore-pipeline model}

To represent the wellbore a pipe with a length of $992 \mathrm{~m}$ and diameter of $0.1 \mathrm{~m}$ was taken and its roughness was set as $2.8 \mathrm{e}-05 \mathrm{~m}$. The reservoir model has discretize the well into 10 zones, and each zone is divided into two sections. As a result the well is divided in to 20 hypothetical sections. A pipe with the same dimensions was taken to represent the base pipe and its roughness was defined as $0.045 \mathrm{~m}$. Similar to the wellbore, it is also divided into 20 sections. By using Figure 5, which shows a single zone of the well, the concept of this model can be described.

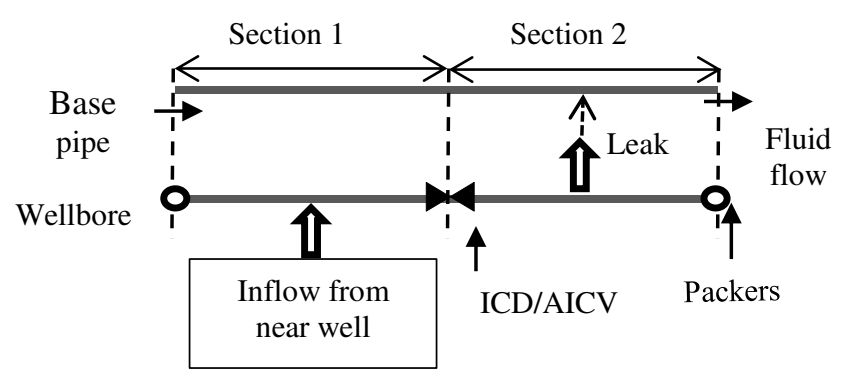

Figure 5. Simplified model of a single section of the well

In Table 4. It is described how the model in Figure 5. is developed within OLGA GUI environment by using inbuilt OLGA modules.

Table 4. Reservoir/well model on OLGA

\begin{tabular}{|l|l|l|}
\hline Component & OLGA module & Description \\
\hline $\begin{array}{l}\text { Inflow } \\
\text { source }\end{array}$ & $\begin{array}{l}\text { Nearwell } \\
\text { source }\end{array}$ & $\begin{array}{l}\text { Reservoir model (Rocx } \\
\text { file) is coupled with this. }\end{array}$ \\
\hline Leak & Leak & $\begin{array}{l}\text { Diameter }-3.5 \mathrm{~cm}, \\
\mathrm{CD}^{1}-1 \\
\text { NO mass transfer } \\
\text { between the phases. } \\
\text { Connects to the pipeline }\end{array}$ \\
\hline ICD/ & Valve/PID & $\begin{array}{l}\text { Valve size is used to } \\
\text { decide the required } \\
\text { pressure drop through the } \\
\text { ICD (typically 20mm). } \\
\text { Controlled } \\
\text { valve }\end{array}$ \\
& & $\begin{array}{l}\text { For AICV, valve opening } \\
\text { is controlled through a } \\
\text { PID controller. }\end{array}$ \\
& & Valve (closed) \\
& & $\begin{array}{l}\text { Opening - 0 (fully } \\
\text { closed), } \\
\text { Diameter - 0.1 m }\end{array}$ \\
\hline Packers & &
\end{tabular}

\subsubsection{AICV modeling}

Parameters of the PID controller used to model the AICVs are defined in Table 5. to get the controlling performance. These parameters were obtained by using trial and error method.

\footnotetext{
${ }^{1} \mathrm{CD}$ - coefficient of discharge
} 
Table 5. PID controller parameters

\begin{tabular}{|l|l|l|}
\hline Parameter & $\begin{array}{l}\text { Value } \\
(\text { AICV) }\end{array}$ & $\begin{array}{l}\text { Value (for flow } \\
\text { choking in ICD) }\end{array}$ \\
\hline Amplification & -0.01 & -0.0001 \\
\hline Bias (Initial signal) & 1 & 1 \\
\hline Integral constant (s) & 50 & 500 \\
\hline $\begin{array}{l}\text { Maximum signal } \\
\text { (maximum opening) }\end{array}$ & 1 & 1 \\
\hline $\begin{array}{l}\text { Minimum signal } \\
\text { (minimum closing) }\end{array}$ & 0.01 & 0.01 \\
\hline
\end{tabular}

\subsection{Simulated cases}

Three main cases were simulated, focusing on three different types of inflow control technologies which are listed in Table 6. A reference case having ICDs with $20 \mathrm{~mm}$ opening, and without choking the total flow was also simulated.

Table 6. Type of inflow control technologies

\begin{tabular}{|l|l|}
\hline Case & Description \\
\hline $\begin{array}{l}\text { Case 1 } \\
\left(\mathrm{ICD}_{\mathrm{ch}}\right)\end{array}$ & $\begin{array}{l}\text { Well having ICDs (20mm opening) } \\
\text { combined with choking of the total flow } \\
\text { from the reservoir. }\end{array}$ \\
\hline $\begin{array}{l}\text { Case 2 } \\
\left(\mathrm{ICD}_{\mathrm{ch}, \mathrm{res}}\right)\end{array}$ & $\begin{array}{l}\text { Installing an ICD having a relatively } \\
\text { higher flow restriction at the high } \\
\text { permeable zone while installing normal } \\
\text { ICDs in the rest of the zones. Total } \\
\text { product rate is also choked when the total } \\
\text { flow rate exceeds the desired value. }\end{array}$ \\
\hline $\left.\begin{array}{l}\text { Case 3 } \\
(\mathrm{AICV}\end{array}{ }_{1 \%}\right)$ & $\begin{array}{l}\text { Well with AICVs having a relative } \\
\text { opening of } 1 \% \text { when the AICV is in } \\
\text { closed position. }\end{array}$ \\
\hline
\end{tabular}

\section{Simulation results}

\subsection{Comparing the basic performances of AICVs and ICDs in fractured reservoirs}

\subsubsection{Accumulated oil and water}

In Figure 6. accumulated volumes of oil and water are plotted for the cases mentioned in Table 6 .
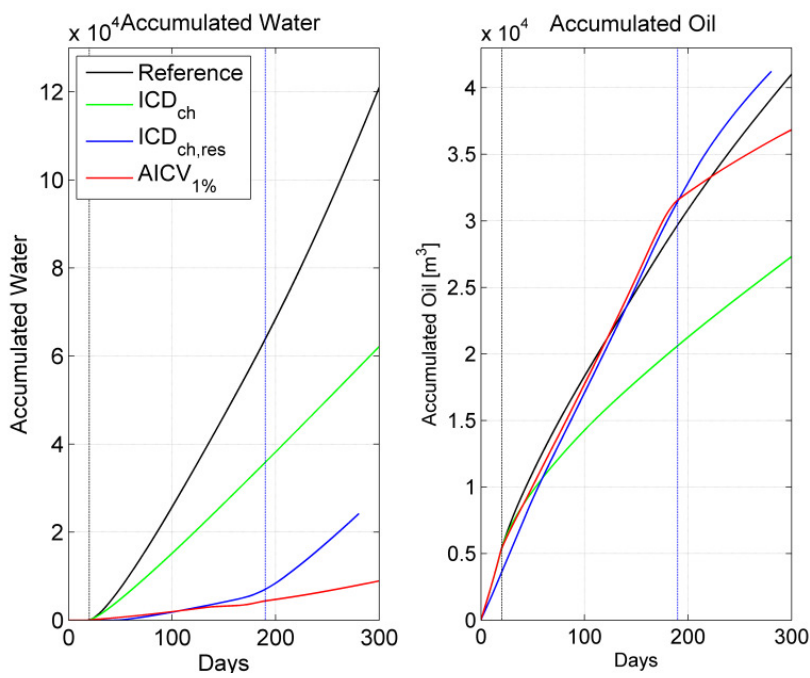

Figure 6. Accumulated oil and water for comparison

According to the Figure 6. it is observed that all the considered inflow control technologies have the capability to reduce the water inflow compared to the reference case. Among the considered inflow control technologies, AICVs have the highest potential in reducing the water inflow. On the other hand, normal ICDs with choked flow have reduced the accumulated oil volume significantly, while the other two methods have been deviated from the reference case slightly

The deviations of the accumulated oil and water volumes, for the different inflow control technologies, can be expressed with respect to the reference case. The relative deviations and the average water cut of the total flow are summarized in the Table 7. These results were obtained on the $281^{\text {st }}$ day of the operation.

Table 7. Accumulated oil/water comparison

\begin{tabular}{|l|l|l|l|}
\hline Case & $\begin{array}{l}\text { Change of oil } \\
\text { accumulation } \\
{[\%]}\end{array}$ & $\begin{array}{l}\text { Change of } \\
\text { water } \\
\text { accumulation } \\
{[\%]}\end{array}$ & $\begin{array}{l}\text { Average } \\
\text { water } \\
\text { cut [\%] }\end{array}$ \\
\hline $\mathrm{ICD}_{\mathrm{ch}}$ & -33.2 & -47.7 & 68.7 \\
\hline $\mathrm{ICD}_{\text {ch,res }}$ & 5.2 & -77.9 & 37.0 \\
\hline $\mathrm{AICV}_{1 \%}$ & -8.1 & -92.7 & 18.2 \\
\hline
\end{tabular}

The restrictions imposed on the fluid inflow to control the water production, have affected a reduction in oil production as well. Based on the amount of accumulated water, the AICVs display a remarkably higher potential in restricting the water inflow. 
By considering the results obtained from Case 1, it can be seen that choking the total flow will not only reduce water production but will also limit the oil production. When it comes to quality of the final product, the reference case has an average water cut of $73.71 \%$. This simulation shows that having relatively low restrictive uniform ICDs with flow choking is not a suitable solution for the water inflow problem in fractured reservoirs.

It is interesting to see that by replacing the normal ICD in the high permeable zone with a more restrictive ICD, the results have been dramatically changed. It has enhanced the accumulated oil volume while the other two inflow control technologies have reduced the amount of oil production. According to Figure 6, until the second breakthrough occurs on the $160^{\text {th }}$ day, flow pattern of the AICV case and the non-uniform ICD case $\left(\mathrm{ICD}_{\mathrm{ch}, \mathrm{res}}\right)$ follow a similar path.

\subsubsection{Oil and water flow rates}

Changes of the oil and water flow rates throughout the production time, especially when the water breakthrough takes place, indicate the positive and negative features of the AICV and non-uniform ICD methods. Oil and water flowrates of the two cases are presented in Figure 7.

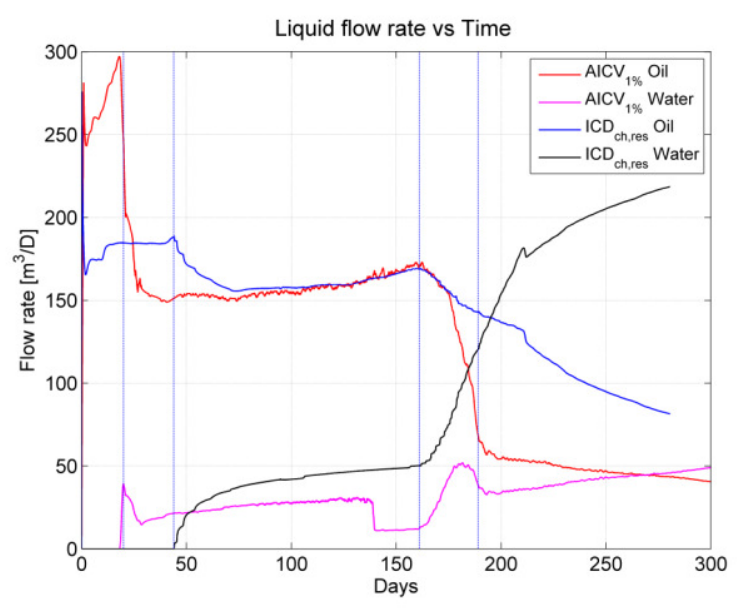

Figure 7. Oil and water flow rate of AICV and $\mathrm{ICD}_{\mathrm{ch}, \text { res }}$ methods

Installing a more restrictive ICD having a higher pressure drop, in the high permeable zone, has delayed the early water breakthrough down to 44 days. Due to the higher pressure though the new ICD; oil production rate has also been reduced.

Non-uniform ICD method has been able to produce $63.46 \%$ more oil compared to AICV methods, at the time of the early water breakthrough. On the other hand it inherits low oil production rates and the inability to control the water inflow when the breakthrough happens. From a practical point of view, it is difficult to locate the exact position of the high permeable zones and hence it is challenging to install more restrictive ICDs within particular zones.

Even though the non-uniform ICD method has been able to delay the first breakthrough, by the time of the second breakthrough happens, it has produced more water and less oil compared to AICV system. In Figure 7. it can be observed that when the second breakthrough happens on the $160^{\text {th }}$ day, the oil production rate rapidly reduces and water flow rate rapidly increases. When observing the relative opening area of the AICVs with respect to time, it takes 20 days for them to reach the closed position (minimum opening). If an AICV takes a relatively long period of time to reach its closed positon, water production rate will also be increased. At the same time, if an AICV has a relatively very small opening at the closed position, oil production rate will also be reduced significantly along with the water inflow rate. As a result the amount of oil being produced after the valves are closed down, is less than the non-uniform ICD method. This is a factor which has to be considered based on the economics of the production. With a smaller opening of the AICV, both oil and water flow rates will be reduced and if the opening area of the valve is set to a higher value at the closed position, it will increase the water and oil production rates.

\subsection{Effects of design parameters of AICV}

\subsubsection{Pressure drop and minimum opening area}

In an AICV, pressure drop across the valve and the allowable flow at the closed positon are design parameters, which can be adjusted depending on the application. Two cases were simulated to see the effect of having a higher pressure drop over the AICV $\left(\mathrm{AICV}_{1 \%, \text { res }}\right)$ and the effect of having a better closing valve $\left(0.25 \% \text { minimum opening, } \mathrm{AICV}_{0.25 \%}\right)_{\text {at }}$ the high permeable zone.
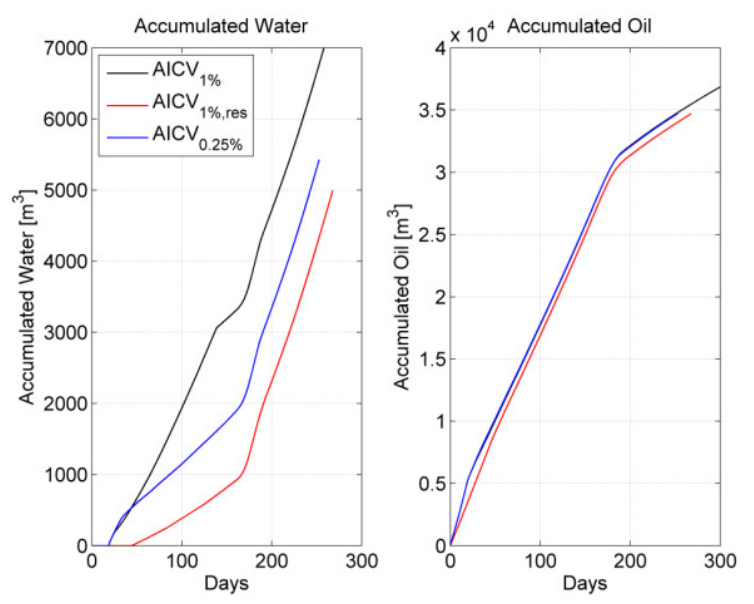

Figure 8. Accumulated water and oil with respect to AICV parameters 
The accumulated oil and water profiles of these two cases are presented in Figure 8. with respect to the accumulated oil and water profiles of uniform AICVs with $1 \%$ minimum opening.

When considering the amount of accumulated water, it can be concluded that having a higher pressure drop is more effective than having a fine closing. This phenomenon is highly depent on the reservoir and fluid properties. In this particular well, reducing the minimum opening down to $0.25 \%$, has no effect on the amount of oil accumulated. Having a higher pressure drop has also reduced the oil accumulation slightly.

If it is required to produce more oil at a higher production rate, minimum opening of the AICVs in the low permeable zones, have to be increased. A case was simulated by having an AICV with both higher pressure drop and a lower opening at the high permeable zone and having AICVs with $2 \%$ opening in rest of the zones. The obtained results are plotted with respect to the results in Figure 8. and it is presented in Figure 9.

As expected the new combination has yielded a higher oil production, but it has also increased the water production as well. The acceptable water cut and the minimum opening area of the AICVs have to be decided based on the economics of the production process.
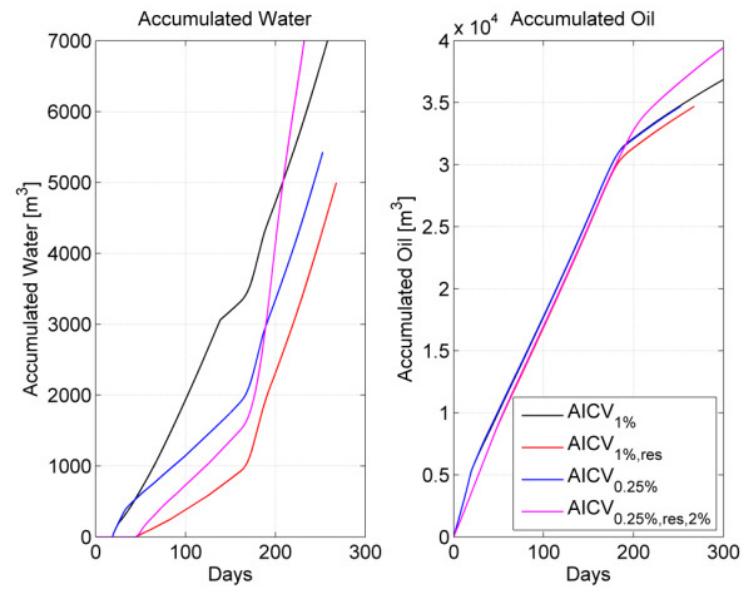

Figure 9. Accumulated oil and water with $2 \%$ opening AICV

\subsubsection{Response time}

Once the water starts to flood into the AICV, it takes a certain period of time for the valve to respond to the change of the fluid properties. As a result the valve will not close as soon as the water breakthrough occurs. In Figure 10, oil and water flow rates of two identical cases having AICVs with different response times are presented. As it can be seen, if the valve closes slowly, water production rate rapidly increases and as a result water accumulation will be increased. However after the AICVs reach their closed positions, both water and oil flow rates will reach the same value regardless of the response time.
From a practical point of view the difference between the two response times might not be significant. But from a simulation point of view, PID controller which is used to represent the AICV has to be tuned properly. Otherwise closing will not be similar to the actual closing function of the AICV and significant errors could occur in the accumulated flows.
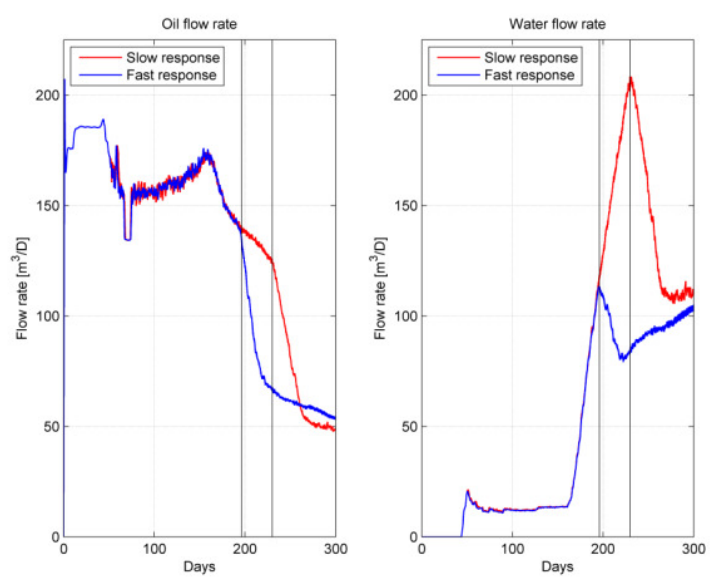

Figure 10. Oil and water flow rates under different response times

\subsection{Functionality of the AICVs and ICDs in homogeneous reservoirs}

For the simulations, a reservoir with a vertical permeability of $100 \mathrm{mD}$ was considered as shown inFigure 4. Accumulated oil and water quantities are plotted in Figure 11. and, the AICVs have reduced the amount of water that is being produced. According to the results obtained, AICVs have been able to reduce the water accumulation by almost $47 \%$. As a side effect of the inflow control, oil production has also been reduced by $7 \%$.
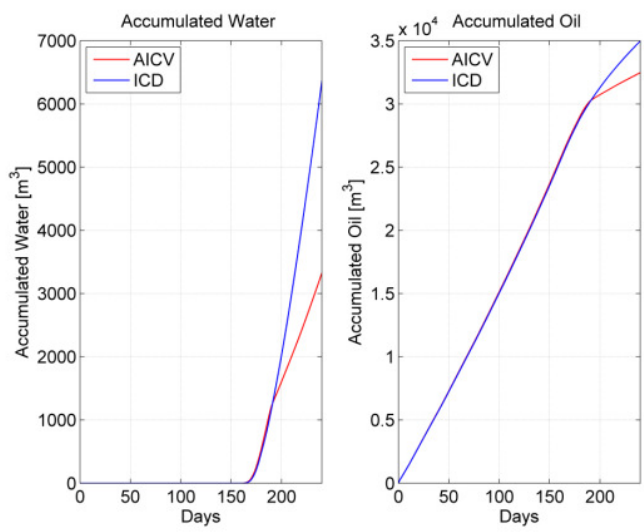

Figure 11. Accumulated water and oil profiles of homogeneous reservoirs

As seen in Figure 11. until the AICVs are closed down, both ICDs and AICVs follow the same flow 
pattern. Once the AICVs are closed down both oil and water inflows are choked down. Therefore the oil accumulation will be less than the normal ICDs. The changes of liquid flow rates are shown in Figure 12.
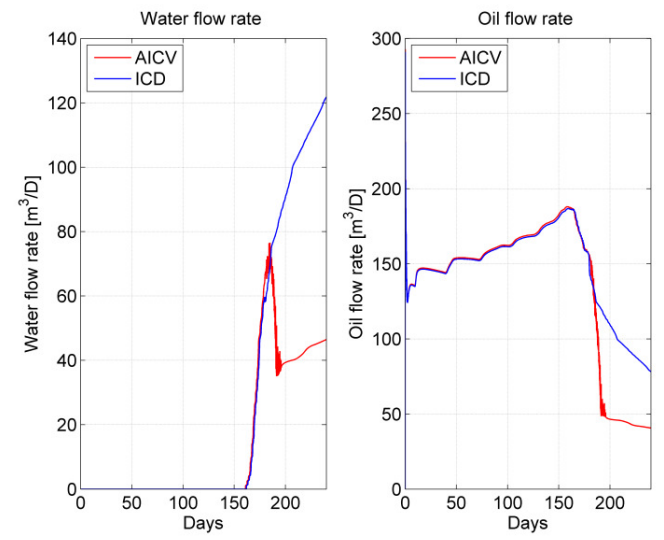

Figure 12. Water and oil flow rates of homogeneous reservoirs

ICDs have only been able to delay the water inflow and once the water starts flooding into the well it has no control over it. Hence water inflow rate is continuously increases while the oil production rate is gradually decreasing. Due to AICV's capability to restrict the inflow, water flow rate is suddenly dropped down to a lower value, when the AICV is closed down. Due to the low viscosity of water, its production rate is gradually increases. As a result when the valve is in the closed position where it cannot restrict the inflow further, water production rate will increase gradually. However AICVs have been able to restrict the water inflow rate down to a significantly lower value compared to the ICDs. As the AICVs are closed down, oil production is also reduced down and continuously decreases due to the production of water.

\subsection{Functionality of the AICVs and ICDs in heterogeneous reservoirs}

As shown in Figure 4, an intermediate reservoir between a fractured and a homogeneous reservoir was also taken for the simulations. The accumulated oil and water volumes are presented in Figure 13.
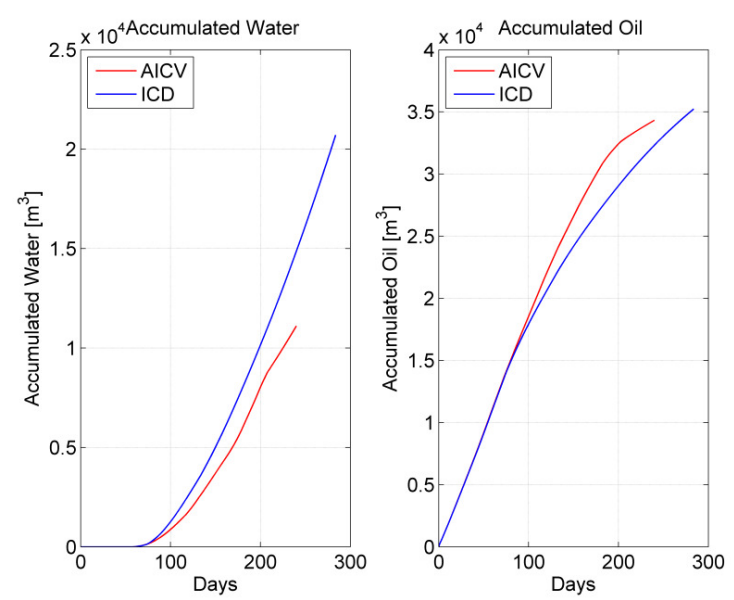

Figure 13. Accumulated water and oil profiles of heterogeneous reservoir

Compared to the accumulated liquid profiles in homogeneous reservoir AICVs in heterogeneous reservoirs have the potential to produce more oil compared to ICDs. The liquid flow rate profiles of the considered heterogeneous reservoir are presented in Figure 14.
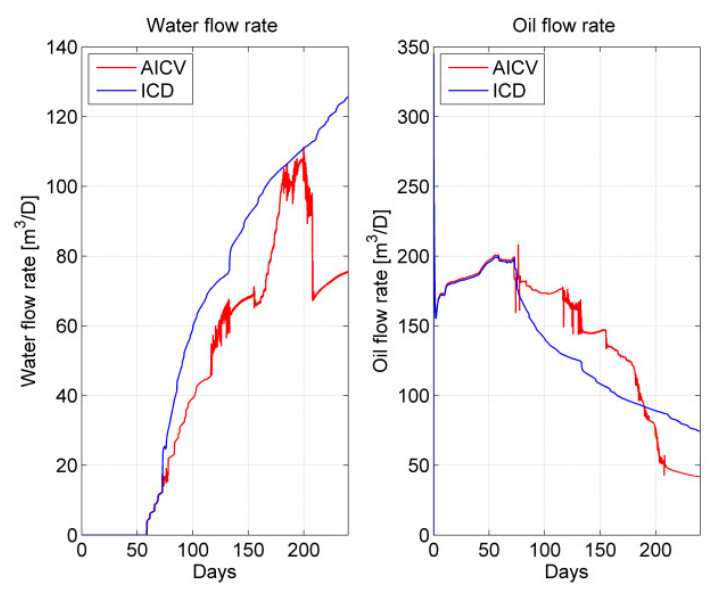

Figure 14. Water and oil flow rates of heterogeneous reservoir

As there are three different permeable zones three water breakthroughs occur during the production. First one occurs on the $55^{\text {th }}$ day and the last one is initiated on $160^{\text {th }}$ day. AICVs will be completely closed by the $210^{\text {th }}$ day. That is why a sudden increase and decrease in water production rate is observed on 160th day and on 210th day respectively. Until the third breakthrough, AICVs have maintained a higher oil production rate. In the ICD system oil production rate has decreased due to the choking of the total flow.

By considering the results obtained for the three types of the reservoirs, AICVs can be effectively used in both fractured and heterogeneous reservoirs. Even though they reduce the water production in 
homogeneous reservoirs, they reduce the amount of oil produced as well.

\section{Discussion}

Under all the conditions, which were taken into consideration during the simulations, AICVs have produced less water than all the other inflow control technologies.

Compared to the uniform ICD system, AICVs have been able to produce more oil in both fractured and heterogeneous reservoirs. In homogeneous reservoirs, as the AICVs choke the inflow of the all the zones simultaneously, oil production rate is reduced compared to the ICDs. This phenomenon can also be seen in the long run operation of heterogeneous and fractured reservoirs. By increasing the allowable flow through the AICV when it is in closed position, it will be able to produce more oil provided that it will produce more water as well.

It has been shown that if it is possible to install an AICV or/and ICD having a relatively higher flow restriction, in the high permeable zone, early water breakthrough in fractured reservoirs can be delayed. It will also increase the amount of oil produce at the time of breakthrough. Also a much lower water inflow rate can be achieved, compared to uniform AICV/ICD systems. The main drawback of this system is that it is difficult to locate the exact location of the high permeable zones and it is also difficult to install a particular inflow control instrument in an exact location.

To conduct accurate simulations of the AICVs, it is important to tune the PID controlling system that is used to represent the AICV. False tuning will lead to slow responses or too many fluctuations, causing significant errors in the final results. Currently the tuning has to be conducted by trial and error method combined with PID condoling theory.

\section{Conclusion}

Based on the obtained results, it can be concluded that the AICVs can be successfully implemented to minimize the water inflow into the base pipe. Due to the choking of the inflow, AICVs will restrict the oil production down to a certain limit as well. By having a higher minimum opening area when the AICV is in closed position, restriction towards the oil production can be minimized. The acceptable limit of the water cut of the final product, has to be decided according to the economic factors.

AICVs are more suitable to be used in heterogeneous and fractured reservoirs. In homogeneous reservoirs it will choke the oil inflow from all the zones and therefore the total oil production is rapidly reduced. If it is possible to have ICDs or AICVs having higher flow restriction properties, installed in the high permeable zone, much better inflow control action can be obtained in fractured reservoirs. But practically it is difficult to install the correct type of AICV at the correct position. But the advantage of AICV is that it will close the water producing zone and produce oil from the other zones

Response time of the AICV plays a vital role in the effectiveness of the AICV. At the time of closing the AICVs, if the water flow rate is almost equal to the oil flow rate, reservoir will produce more water even after the inflows are choked. (due to the minimum allowable flow through AICV).

All the results obtained by the simulations are required to be validated by conducting experimental work. And further study has to be conducted in homogeneous reservoirs, to see how the performance of the AICV can be enhanced.

\section{Abbreviations}

$\begin{array}{ll}\text { AICV } & : \text { Autonomous Inflow Control Valve } \\ \text { GLR } & : \text { Gas Liquid Ratio } \\ \text { GOR } & : \text { Gas Oil Ratio } \\ \text { ICD } & : \text { Inflow Control Device } \\ \text { ICV } & \text { : Inflow Control Valve }\end{array}$

\section{References}

A. Hart. 2013. "A review of technologies for transporting heavy crude oil and bitumen via pipelines." Journal of Petroleum Exploration and Production Technology:110. doi: 10.1007/s13202-013-0086-6.

B. Hu, J. Sagen, G. Chupin, T. Haugset, A. Ek, and T. Sommersel. 2007. "Integrated WellboreReservoir Dynamic Simulation,." Asia Pacific Oil and Gas Conference and Exhibition.

F. T. Al-Khelaiwi, V. M. Birchenko, M. R. Konopczynski, and D. Davies. 2010. "Advanced Wells: A Comprehensive Approach to the Selection Between Passive and Active Inflow-Control Completions." SPE Production \& Operations 25:305-326. doi: http://dx.doi.org/10.2118/132976-PA.

M. Halvorsen, G. Elseth, and O. M. Nævdal. 2012. "Increased oil production at Troll by autonomous inflow control with RCP valves." SPE Annual Technical Conference and Exhibition.

Mathiesen, H. A. Vidar. 2013a. "Increased oil recovery of an old well, recompleted with Autonomous Inflow Control Valve (AICV)." ADIPEC 2013 Technical 
Conference, Abu Dhabi, United Arab Emirates.

Mathiesen, V. 2013b. "Autonomous gas/water shutoff in field with gas/water breakthrough." SPE Aberdeen Summit Series Seminar.

P. Fernandes, Z. Li, and D. Zhu. 2009.

"Understanding the roles of inflow-control devices in optimizing horizontal-well performance." PE Annual Technical Conference and Exhibition.

Peaceman, D. W. 2000. Fundamentals of numerical reservoir simulation: Elsevier.

R. A. F. S. Moghaddam, H. Aakre, B. M. Halvorsen. 2013. "Near well simulations of heavy oil production with ICD completion." Computational Methods in Multiphase Flow VII 79:499-509.

S.D.Joshi. 2003. "Cost/benefits of horizontal wells." SPE Western Regional/AAPG Pacific Section Joint Meeting. 